
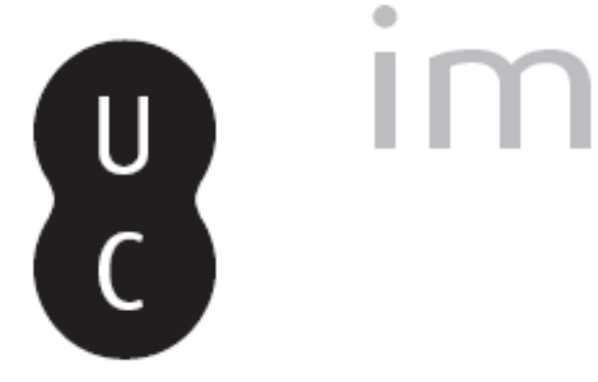

\title{
partilim
}

\section{Dou para que me dês... um obrigado!}
Autor(es):
Santos, Nídia Catorze
Publicado por: Associação Portuguesa de Estudos Clássicos; Instituto de Estudos Clássicos

URL persistente:

URl:http://hdl.handle.net/10316.2/30324

DOI:

DOI:http://dx.doi.org/10.14195/0872-2110_56_12

Accessed : $\quad$ 26-Apr-2023 09:25:19

A navegação consulta e descarregamento dos títulos inseridos nas Bibliotecas Digitais UC Digitalis, UC Pombalina e UC Impactum, pressupõem a aceitação plena e sem reservas dos Termos e Condições de Uso destas Bibliotecas Digitais, disponíveis em https://digitalis.uc.pt/pt-pt/termos.

Conforme exposto nos referidos Termos e Condições de Uso, o descarregamento de títulos de acesso restrito requer uma licença válida de autorização devendo o utilizador aceder ao(s) documento(s) a partir de um endereço de IP da instituição detentora da supramencionada licença.

Ao utilizador é apenas permitido o descarregamento para uso pessoal, pelo que o emprego do(s) título(s) descarregado(s) para outro fim, designadamente comercial, carece de autorização do respetivo autor ou editor da obra.

Na medida em que todas as obras da UC Digitalis se encontram protegidas pelo Código do Direito de Autor e Direitos Conexos e demais legislação aplicável, toda a cópia, parcial ou total, deste documento, nos casos em que é legalmente admitida, deverá conter ou fazer-se acompanhar por este aviso. 


\section{Boletim de \\ Estudos Clássicos}

Associação Portuguesa de Estudos Clássicos Instituto de Estudos Clássicos

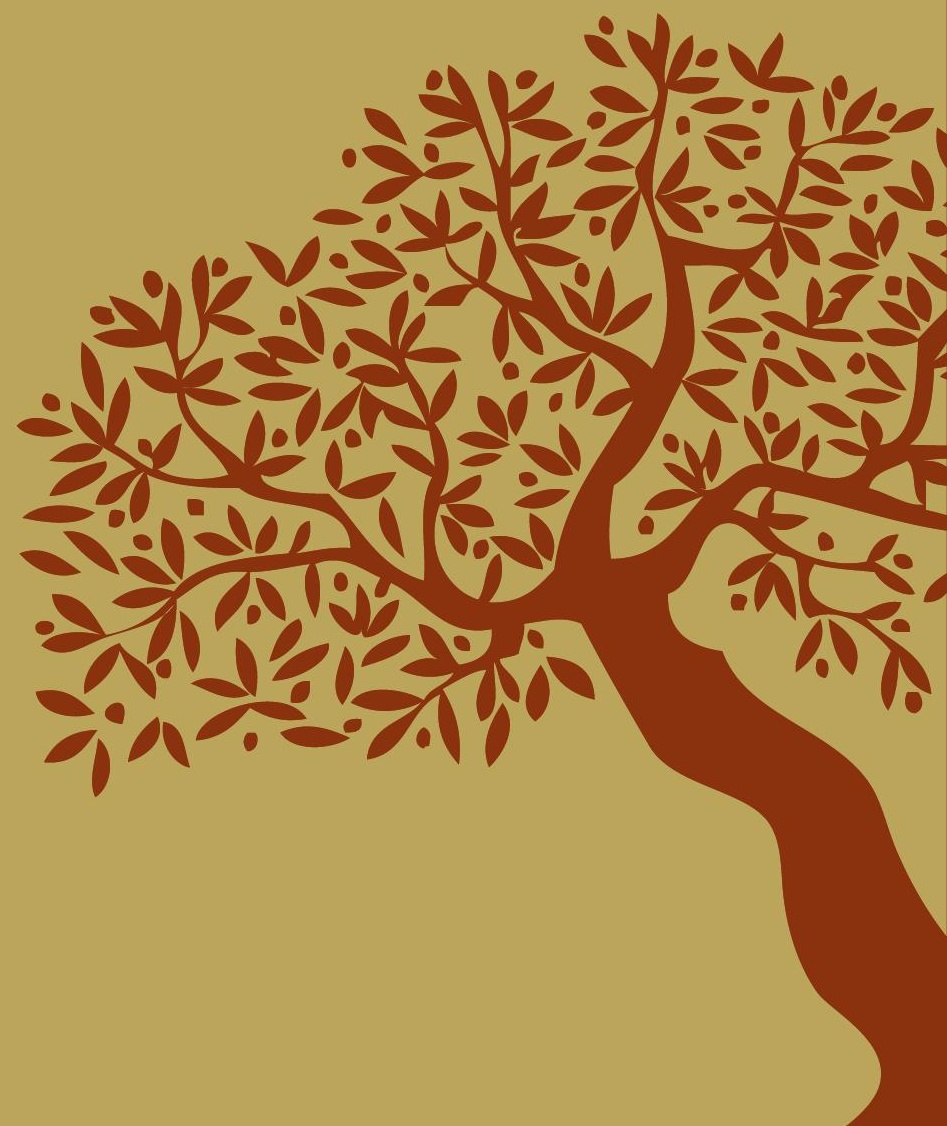

Coimbra

Dezembro de 2011 


\section{DOU PARA QUE ME DÊS... UM OBRIGADO!}

O mundo clássico na banda desenhada através da partilha de conteúdos online

Numa época centrada nas novas tecnologias e na ciência, em que por todo o mundo ocidental se anuncia o fim dos Estudos Clássicos, com várias universidades a extinguirem ou reduzirem o financiamento aos seus centros devido a dificuldades económicas, a Internet é cada vez mais a guardiã do imenso património literário e mitológico da Antiguidade Clássica, nos mais diversos suportes. Em especial, o universo da banda desenhada tem-se destacado. A um ritmo anual, a Marvel tem lançado mini-séries com Hércules como protagonista ${ }^{1}$ e 2011 não foi excepção: Herc, que conta já com nove números publicados, é a nova saga dedicada ao herói grego e é anunciada como "a bold new era for the Lion of Olympus". Mas esta presença, não se limita à Marvel e também a Avatar lançou nos Estados Unidos uma edição em seis números, dos quais quatro já estão publicados, onde apresenta uma nova versão da história de Calígula, que dá também o nome à $\mathrm{BD}$, um homem ébrio de poder, mas possuído igualmente por ele. A apresentação, onde é notória a influência dos trailers a que o cinema nos habituou, descreve o seu reinado como "an age of depravity, one man's appetites horrified the entire Roman Empire. The very Empire he ruled. Some stories are passed from one generation to the next only in secret. Told in hushed whispers as the very words are too horrific to speak aloud for fear they offend the Gods. A Roman Empire built on the blood of its people, a ruler who began as a generous man but who ended as the most debased of monarchs. One name still speaks volumes of how absolute power can corrupt - Caligula (..)". Por seu lado, a Campfire que recuperou a história da retirada dos dez mil, contada por Xenofonte, em 400 BC: The Story of the Ten Thousand segue-lhe o exemplo

${ }^{1}$ A título de exemplo destacamos apenas: Hercules (2005), Marvel Aventures. The Avengers (2006), Hercules. The Thracian Wars (2008), Incredible Hercules (2008-2010), Hulk vs Hercules: When Titans Collide (2008), Hercules: The Knives of Kush (2009), Hercules: Fall of an Avenger (2010), Hercules: Twilight of a God (2010) ou Wolverine/Hercules: Myths, Monsters \& Mutants (2010). 
e recupera na citação de Virgílio (Aen. 10.284) e na ilustração da capa, o imaginário do Alexandre o Grande de Oliver Stone: "Fortune favors the bold... They were an unstoppable force, hired to take the crown from the King of Persia. They were a fearless army of Greek soldiers, and one hundred thousand men fighting as one. They were led by the finest and most courageous generals in all of Greece. They were being led to unimaginable wealth, but that was days ago. Now their leaders are dead and their army has scattered. Now their numbers have fallen to ten thousand and nothing remains but fear. Now they are men praying not for victory, but for the slim chance of living one more day. Cut off by impassable terrain and pursued by an army of one million enemy soldiers; they must stand together to survive. To find their way home, one of their own must lead them. And to live one more day ...they must fight."

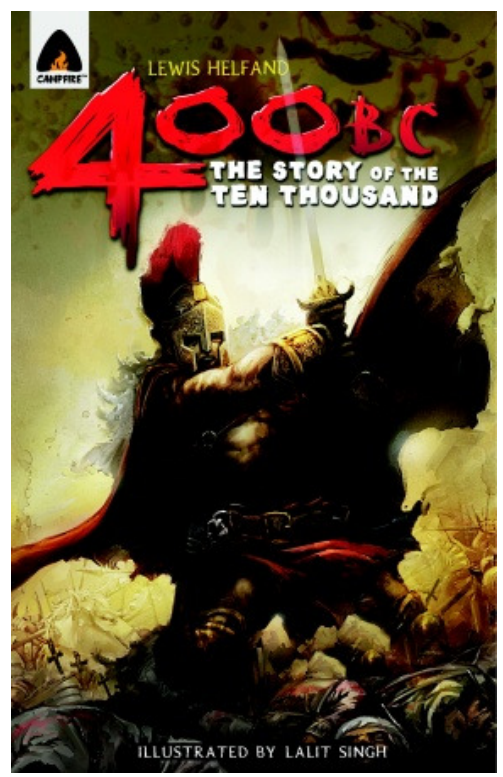

Mas mais surpreendente que a adaptação da temática clássica é a divulgação e recepção que estes comics têm na Internet e são estes dois últimos aspectos que iremos aqui desenvolver, em especial na banda desenhada latino-americana e espanhola das décadas de 40 a 60. 
Veículo de transmissão e de comunicação por excelência do nosso tempo, a Internet teve um desenvolvimento exponencial na última década. A massificação do acesso à Internet foi acompanhada pela profileração de todo o tipo de blogs pessoais e de fóruns, estes últimos a exigirem registo prévio (gratuito) para se aceder aos conteúdos ${ }^{2}$ partilhados pelos membros. A organização destes conteúdos acaba por ser semelhante em todos: filmes, séries, banda desenhada, música, informática, telemóveis, fotografia, entre outros. Estes, por sua vez, introduziram novos anglicismos no vocabulário, como links, torrents ou emule, de forma a se aceder aos conteúdos que nunca estão alojados nos próprios sites, mas em sites de armazenamento. Estas comunidades são definidas por três ideais - partilha, gratuitidade, liberdade que levantam, todavia, questões ético-legais. Questões que têm sido, todavia, ignoradas pelos internautas que consideram o espaço virtual um local sem fronteiras, e por não ter existência física, onde os direitos de autor e a legislação dos países não têm aplicação, apesar dos processos jurídicos movidos pelas poderosas indústrias do entretenimento e mais recentemente, pela indústria livreira, preocupada pela crescente partilha de ebooks online. Estes processos, que não têm tido qualquer impacto nas comunidades online, mostraram todavia a inabilidade daquelas em lidar com a comunidade virtual. A conjugação destes dois fenómenos, a massificação do acesso à internet $\mathrm{e} o$ desenvolvimento das comunidades virtuais, através de blogs e fóruns, foi acompanhada pela chegada ao mercado de scanners de boa qualidade a preços acessíveis, o que por sua vez os transformou em objectos de uso quotidiano para muitos de nós, foi fundamental para a preservação e divulgação, a uma escala inimaginável há alguns anos, de muitos comics que tinham ao longo das décadas, caído no esquecimento.

Neste "admirável mundo novo", os fóruns e blogs dedicados à banda desenhada oferecem um espaço onde os fãs se encontram para trocar informações, trocar ou vender comics. Se muitos são apenas espaços de divulgação, outros destacam-se pelos conteúdos que partilham e, a par das bandas desenhadas organizadas pela origem, americana, europeia, sulamericana, underground ou manga, é possível encontrar ainda instruções para a obtenção de uma boa digitalização, os respectivos programas para ler as bandas desenhadas em suporte digital e ainda os indispensáveis catálogos das

2 A organização destes conteúdos acaba por ser semelhante: filmes, séries, banda desenhada, música, informática, telemóveis, fotografia, entre outros, que por sua vez se subdividem em outras categorias. 
publicações de cada editora. A digitalização e a subsequente partilha são a única forma de muitos coleccionadores completarem as respectivas colecções, iniciadas com frequência durante a infância. Devemos salientar também que muitas destas bandas desenhadas, principalmente as latinoamericanas ou espanholas, são praticamente impossíveis de encontrar à venda. A digitalização não é, todavia, a etapa final, uma vez que a idade de muitas delas e o estado de conservação obrigam a retoques para melhorar a qualidade das imagens. É igualmente frequente os fãs, além de digitalizarem a obra, ainda a traduzirem para a língua materna, no caso de esta ainda não existir. Este esforço individual de cidadãos anónimos afigura-se comparável à iniciativa que levou à fundação em 1996, do archive.org, um dos sites mais interessantes do ciberespaço e uma organização sem fins lucrativos, com o objectivo expresso de construir uma biblioteca na Internet, que oferecesse um acesso permanente a investigadores, historiadores, estudantes e público em geral, às colecções históricas que existam, em formato digital e sem direitos de autor.

Este esforço desinteressado, além de revelar verdadeiros tesouros da banda desenhada, permite alargar o âmbito dos estudos sobre o cinema histórico, e em especial sobre o Peplum, para realizar o contraponto das influências mútuas entre a sétima e a nona arte. Em ambas, a exactidão histórica não era o mais importante, à época. Ainda que as editoras latinoamericanas e espanholas apresentassem, desde a década de 50 aos seus leitores, traduções cuidadas de comics norte-americanos, não descuidaram a criação de séries e heróis próprios. De origem mexicana e fundada em 1949, a Editoral Novaro está indubitavelmente ligada, tal como acontece com a Editorial Maga (fundada em 1951) em Espanha, à Golden Age dos comics latinos. Destacou-se por apresentar as suas bandas desenhadas todas a cor, ao contrário do que acontecia com as restantes editoras, onde apenas a capa era a cores e a história no interior era apresentada a preto e branco. Nos trinta e cinco anos seguintes lançou em exclusivo, no mercado latino-americano e espanhol, os títulos mais prestigiados do comic norte-americano, mas apostou igualmente na produção própria através do lançamento de títulos didácticos como Vidas Ejemplares (1954), Vidas Ilustres (1956) ou Mujeres Célebres (1961), onde foram apresentadas, respectivamente, as vidas de santos, papas, beatos e outras personalidades da Igreja Católica, personagens históricas célebres e, finalmente, as personagens femininas mais marcantes da história. Estas colecções aproveitavam o nicho de mercado criado pelo catolicismo praticado pela esmagadora maioria da população ibero-americana. Também 
Espanha seguiu esta tendência na banda desenhada e nas décadas de 40 a 60, especialmente, o Império Romano e o Cristianismo emergente foram uma presença constante nos comics publicados semanalmente. Esta presença pode ser considerada um reflexo do regime franquista que governava o país e que se apropriou do passado romano, desde o conceito de império ao estilo monumental, passando pela iconografia e simbologia da época, enquanto os movimentos católicos, por seu lado, se empenharam na construção de uma sociedade cristã, incutindo nas gerações mais jovens valores como o heroísmo, o martírio ou sacrifício, alicerçados na devoção a Deus e ao próprio Franco, no respeito à autoridade, ordem e hierarquia.

Nas bandas desenhadas que apresentamos de seguida, e que podem ser encontradas completas na Internet, os paralelos com o Peplum, género cinematográfico, conhecido também como filmes de "sandália e espada", de temática antiga, que se estende desde a antiguidade oriental à queda do império romano, e que se caracteriza pelos heróis musculados "enfiados" em mini-túnicas, governantes diabólicos e tirânicos, lutas de espada, batalhas, feras e ambientes exóticos, além dos anacronismos históricos que apresentam nos enredos. Muitos destes filmes foram produzidos e filmados na Europa e tornaram-se extremamente populares entre o público juvenil de ambos os lados do Atlântico, a partir da década de 50. Perante estas publicações e as que ainda se aguardam num qualquer site perto de nós, resta-nos o conforto das palavras de Mark Twain, ele próprio considerado, no nosso tempo, um autor clássico: " the reports of my death are greatly exaggerated" e dizer obrigado, a única recompensa que nos é pedida por quem partilha estes contéudos.

Viriato y la Destrucción de Numancia (1942)

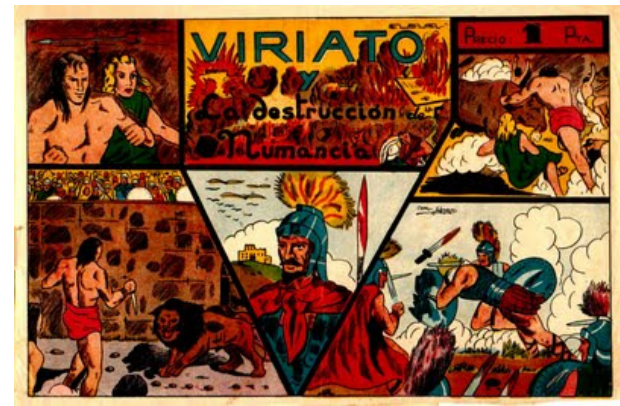


Este número da Editoral Marco apresenta os feitos de Viriato, sua luta contra os Romanos, feitos que foram engrandecidos ao máximo pelo regime de Franco. Depois de ser traído e assassinado, as suas tropas refugiam-se na cidade de Numância e resistem heroicamente durante 14 anos ao cerco das legiões romanas.

\section{Orlan El Luchador Invencible (1947)}

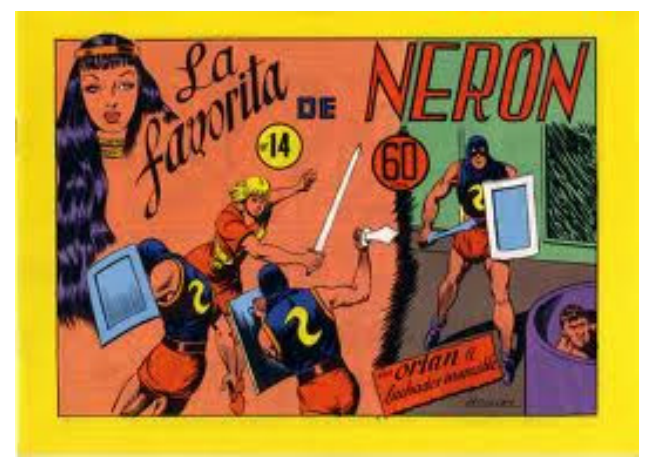

Mais uma colecção da Editorial Marco, desta vez passada no reinado de Nero onde se retrata uma guerra entre Romanos e Vikings, que apesar de pior armados se defenderam com bravura, sendo Orlan, o herói desta banda desenhada, o mais jovem e corajoso dos Vikings. A escolha do reinado de Nero como pano de fundo pode ser já uma influência dos filmes históricos que faziam sucesso à época.

El Libertador (1950)

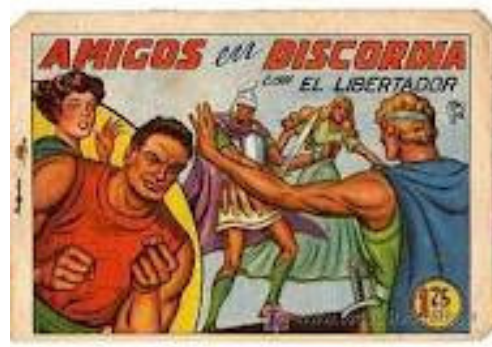


A acção desta banda desenhada da Editoral Garga decorre, como acontece no El Defensor de la Cruz, na Roma de Diocleciano, por volta de 303 d.C., quando o cristianismo emergente era ferozmente reprimido pelas autoridades romanas. O herói é Cláudio Marco, um patrício, atleta formidável que se apaixona por uma patrícia de grande beleza e convertida ao cristianismo. De espírito bondoso, Cláudio deixa-se atrair pela fé da amada e, apesar de a assistência às reuniões cristãs ser punida com a morte, oferece a própria residência como local de reunião dos crentes.

\section{El Defensor de la Cruz (1954-1955)}

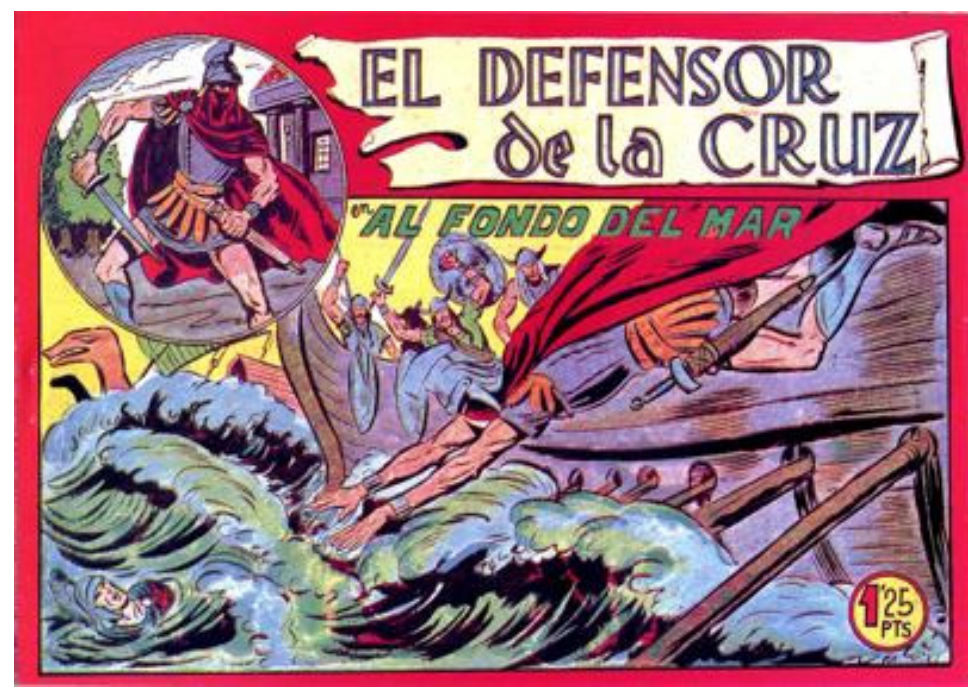

Publicado semanalmente pela Editorial Maga, El Defensor de la Cruz foi a primeira colecção da editora inspirada em temas bíblicos. A acção estende-se por cinquenta e quatro números e um almanaque (1957), na Roma governada por Diocleciano (284-305 d.C.). O herói, filho de um centurião e de uma patrícia e conhecido apenas como "El Defensor de la Cruz", oculta a sua identidade atrás de uma máscara para salvar cristãos destinados às arenas. Entre as personagens secundárias destaca-se o vilão, Casiano Malino, general romano que persegue com extrema crueldade a própria esposa e filha e, ainda Braúlio, devido à fé cristã partilhada por eles. 


\section{El Jabato (1958-1966)}

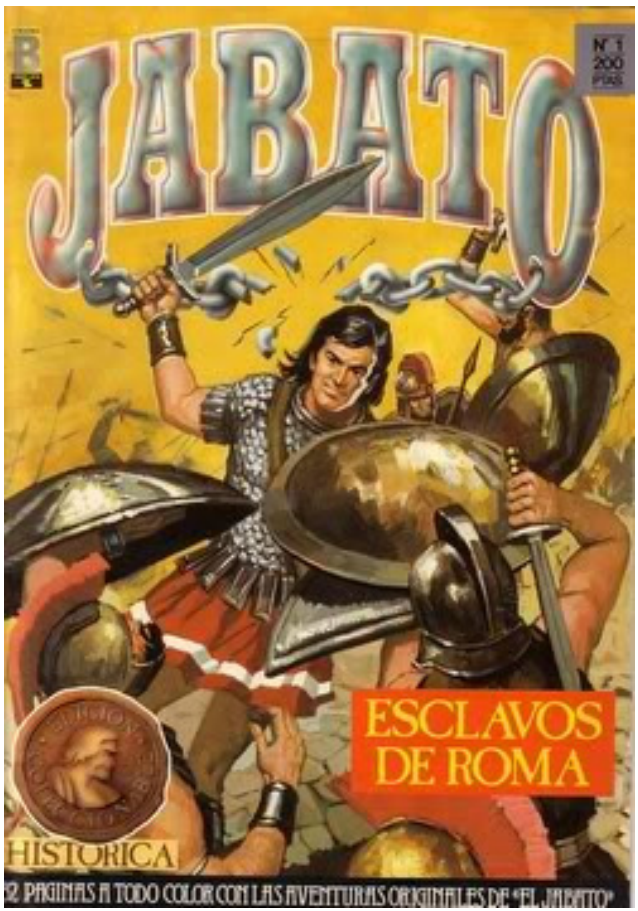

El Jabato, publicado pela Editorial Bruguera e nascido na esteira do $E l$ Capitán Trueno, converteu-se numa das bandas desenhadas mais famosas do país vizinho, apesar dos anacronismos históricos que apresenta. A época histórica não é claramente definida e são vários os imperadores citados ao longo dos 381 números que foram publicados até 1966: Nero, Trajano, Tito ou o fictício imperador Sula. De origem hispana, Jabato faz-se acompanhar de um curioso grupo de companheiros: Taurus, o gigante comilão, Cláudia, uma patrícia romana convertida ao cristianismo e Fideo de Mileto, um poeta grego que os massacra com os seus longos poemas onde celebra os seus feitos. Considerados foragidos perigosos pelos Romanos, que se esforçam por os capturar, sempre que o grupo se aproximava das fronteiras do Império, não hesitam em ajudar os povos que se opõem à ordem romana ou a tiranos mais ou menos exóticos. 
Ayax, El Griego (1960)

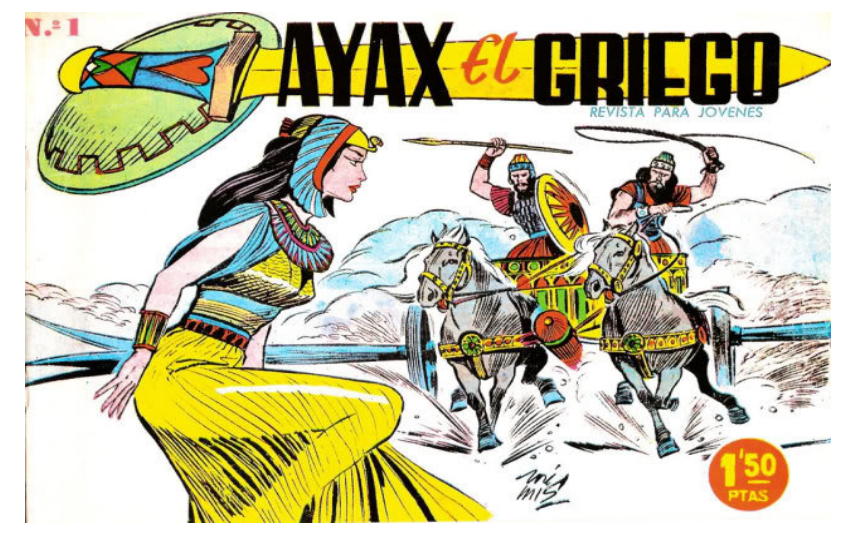

Apresentada como "todos los pueblos de la Antiguedad en feroz lucha por la conquista del poder. Egípcios! Persas! Los feroces Hítitas. Todos desfilan en continua acción por las páginas de este magnifico cuaderno", esta colecção de vinte números, publicada pela Editorial Creo, retrata as aventuras de um soldado grego no país dos faraós, onde se reconhecem as deambulações de Ulisses.

\section{El Coloso / El Príncipe de Rodas (1960)}

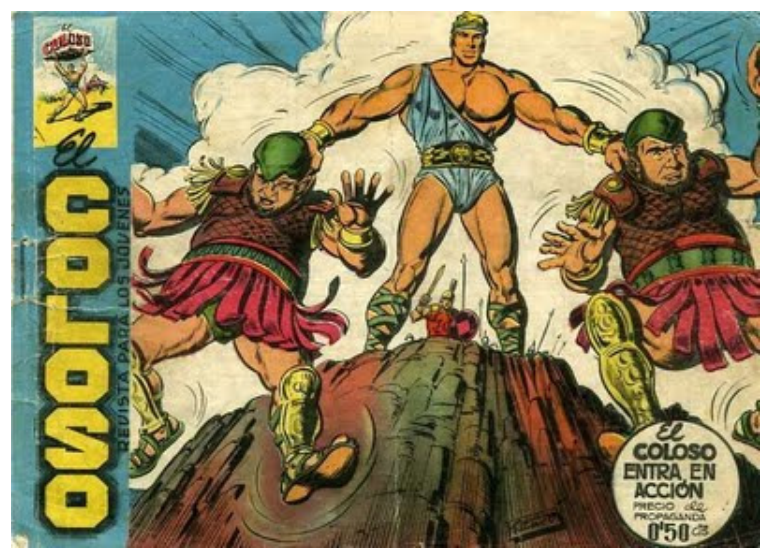


Publicação da Editorial Maga, El Coloso / El Príncipe de Rodas, conta a história de um príncipe "El Coloso", legítimo herdeiro do trono de Rodes, que por morte do rei, seu pai, foi vendido como escravo, pelo próprio tio, Milón. Todas as aventuras giram em torno da busca pelo anel real, única prova que pode levar o usurpador a abandonar o trono e que o herói entregou a Ismene como prova do seu amor. As aventuras prolongaram-se por oitenta e três números, durante os quais vários mitos gregos como o dos Argonautas ou Teseu foram revisitados. Apresenta ainda muitas semelhanças com o peplum italiano, em especial com os filmes dedicados às aventuras de Hércules. A partir do número trinta e seis mudou o nome para El Príncipe de Rodas.

\section{Titan (1961)}

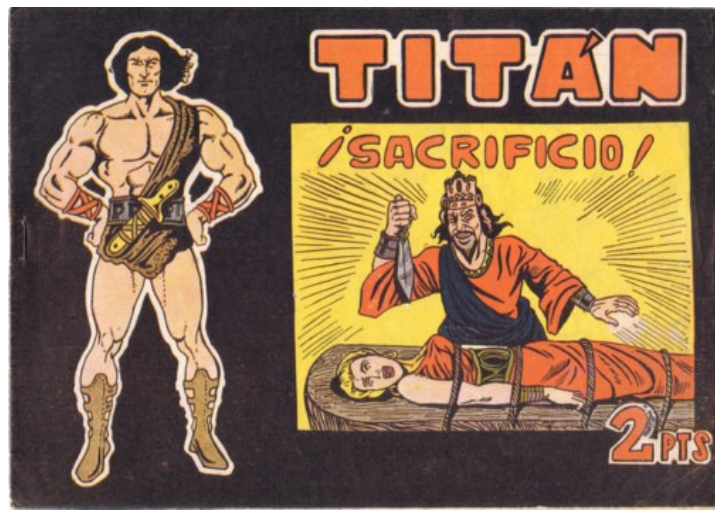

Publicada pela Editorial Acropolis e composta por quarenta números, a história transportava os leitores para a Hispânia Pré-Romana, na época dos primeiros contactos entre indígenas e fenícios. "Titan", o herói, apresentado como um "autêntico exemplar da raça hispana, todo brio, coragem e nobreza de coração", é espantosamente parecido com o actor norteamericano Victor Mature e, coincidência ou não, deve o seu sobrenome à sua força prodigiosa, que levou a que fosse descrito como o "valente e hérculeo Ibero". Esta banda desenhada destaca-se pela época histórica escolhida para palco das aventuras de "Titan", o que permite a abordagem de outras realidades históricas além da greco-romana. 


\section{Coraza (1962)}

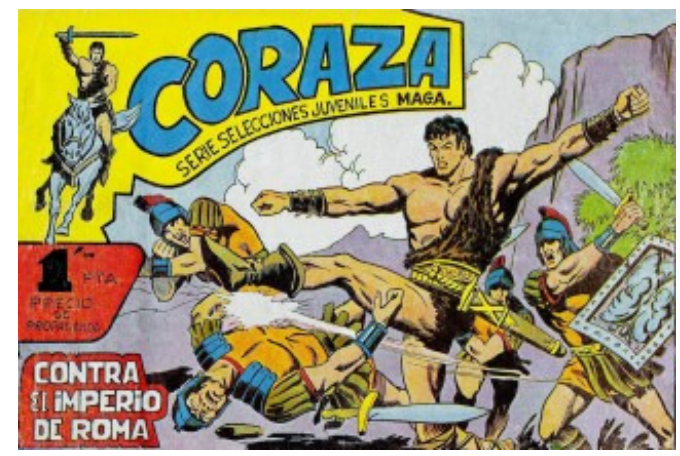

Passada na Hispânia, Coraza conta a história de um líder celtibero, Valério, mais conhecido por "Coraza", cujos homens se opõem aos exércitos romanos invasores. Os infortúnios que se abatem sobre ele, provocados pela traição e inveja de alguns dos seus companheiros, testam a sua integridade até ao limite. A colecção, uma vez mais da Editorial Maga, é composta por sessenta e quatro números que tiveram uma publicação semanal.

El Príncipe de Rodas (1962-1963)

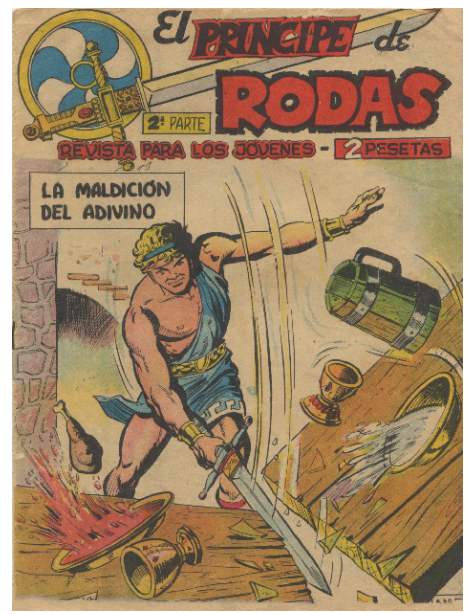


Apesar de manter o nome da edição de 1960, esta segunda parte não é uma sequela e, enquanto a primeira parte teve como palco a Grécia antiga, esta decorre nos últimos anos do Império Romano, durante as invasões bárbaras. No total, foram publicados cinquenta e seis números semanalmente pela Editoral Maga.

\section{Espártaco (1964)}

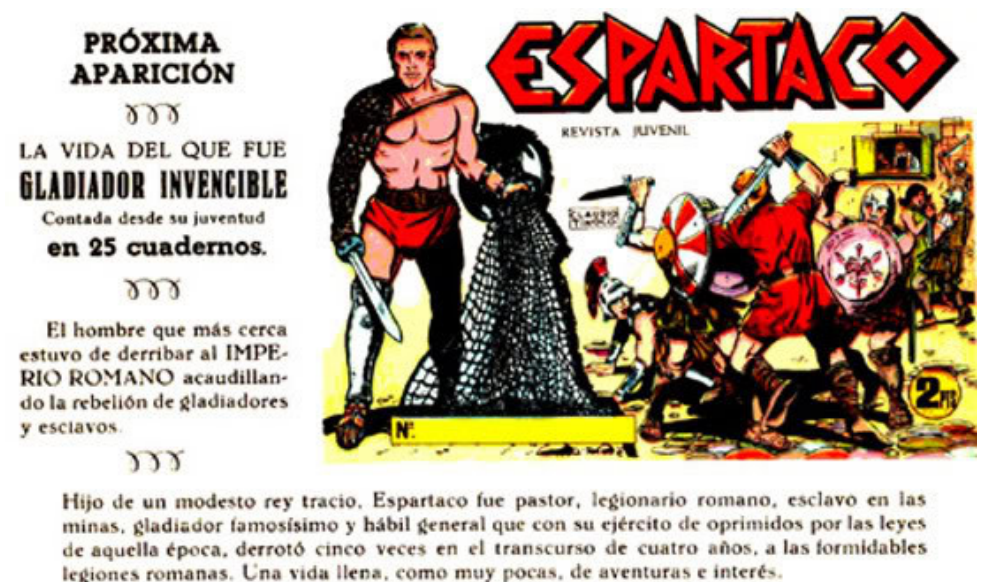

Aunque os comunicaremos su salida desde las contreportadas de JERONIMO

no dejeil de estar atentos a los Kioscos, para no perderos ningún número.

EDICIONES GALAOR

Quatro anos depois da estreia da adaptação de Stanley Kubrick da obra de Howward Fast, Spartacus, a Editorial Galaor lançou esta banda desenhada, cujo herói é claramente inspirado em Kirk Douglas, o protagonista da película. Espártaco surge aqui como filho de Lâmaco, rei de algumas tribos trácias, um jovem pastor e lenhador antes da chegada dos romanos, que será reduzido à escravatura e posteriormente irá liderar a mais famosa das revoltas dos escravos. Com uma tiragem semanal, foram publicados 26 números e em 1968 a colecção foi re-editada. 


\section{Marco, El Gladiador (1964)}

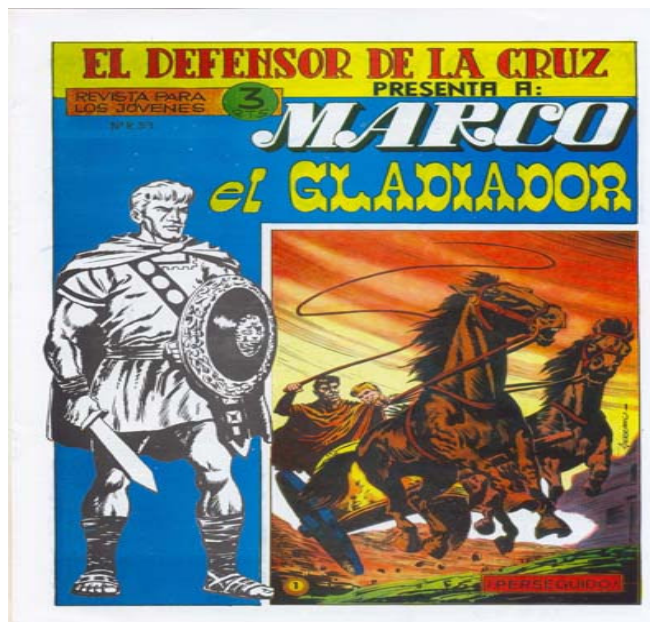

Mais uma publicação da Editorial Maga com o desenho do britânico Don Lawrence. Conta a história de um gladiador famoso, que viaja até à distante Londinium, na Britânia, em busca de Cumnor, seu irmão.

\section{El Libertador (1965)}

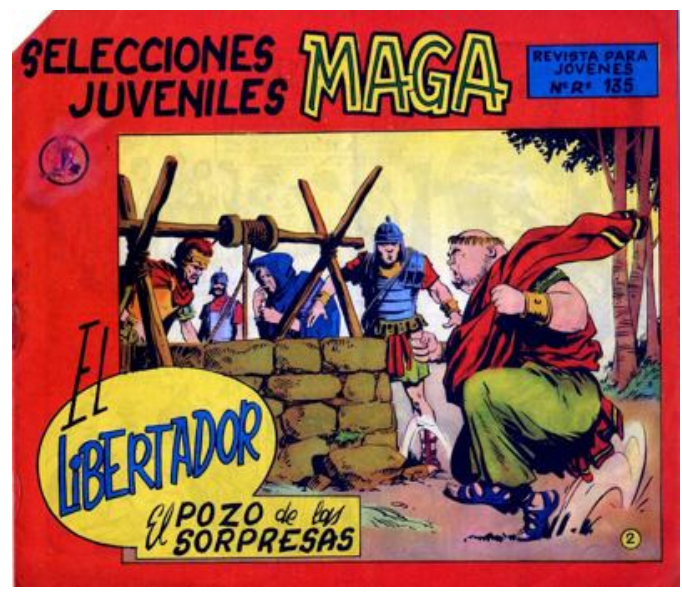


Na província da Tarraconense, na Hispânia, durante o reinado de Galba, surge um herói improvável, Ambrósio Tarraco, que reúne um exército de camponeses dispostos a segui-lo, para combater a tirania do governador local, Caio Justino, apesar de ser seu amigo pessoal.

Joyas de la Mitologia (1963)
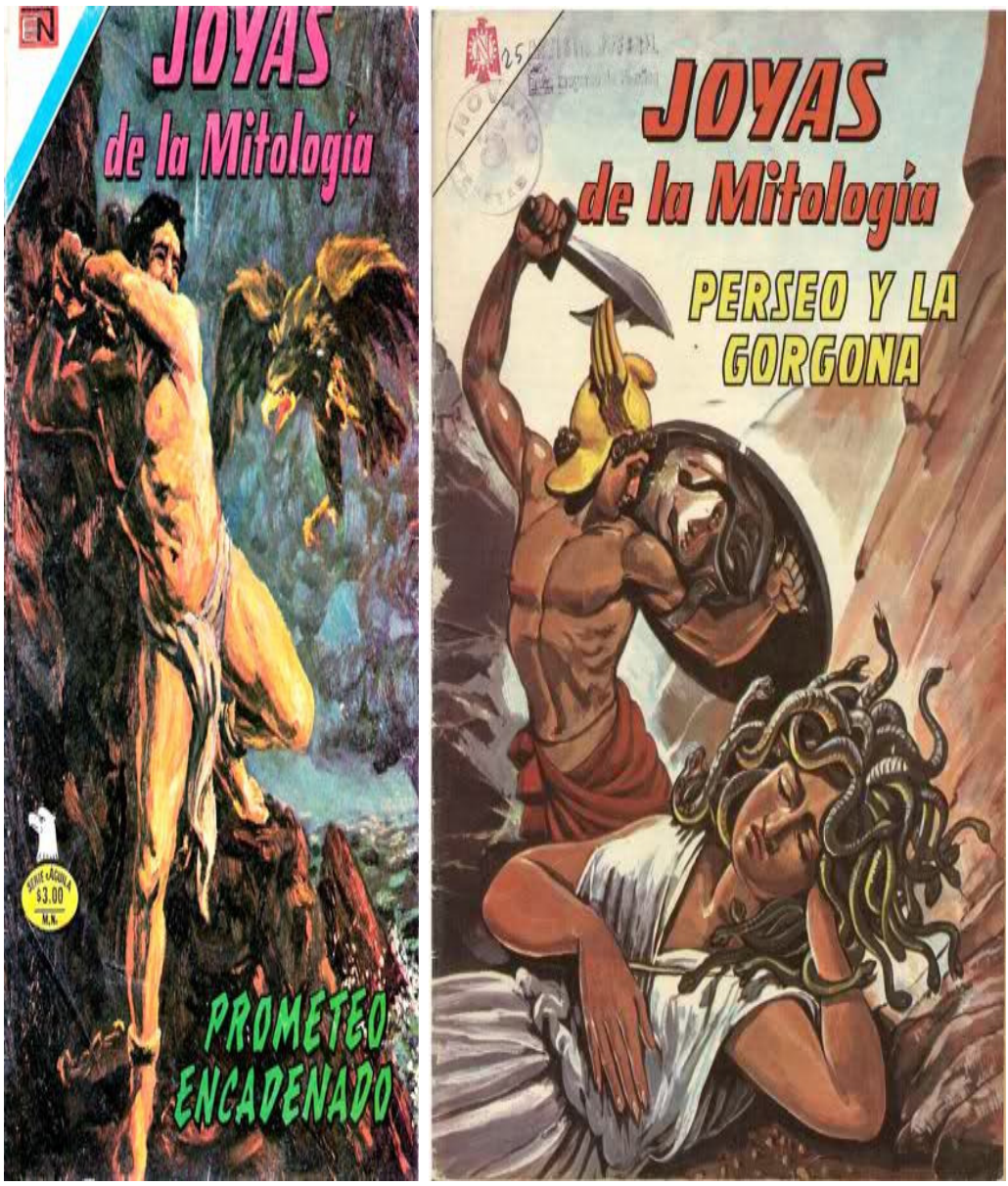
Publicada pela Editorial Novaro esta colecção, como o seu nome indica, apresenta a mitologia de várias culturas e civilizações: greco-romana (números 1-46 e 174-557), sul-americana, egípcia, hindu, nórdica, persa, chinesa, japonesa, australiana, irlandesa e eslava. Assinala-se todavia, a preponderância da mitologia greco-romana sobre as restantes, onde encontramos revisitados os mitos ligados à guerra de Tróia, à tragédia e ainda os heróis e deuses, como Hércules e os Argonautas, Perseu ou Midas.

NÍDIA CATORZE SANTOS 